\title{
Fabrication of Bis-Quaternary Ammonium Salt as an Efficient Bactericidal Weapon Against Escherichia coli and Staphylococcus aureus
}

\author{
Zhiyong Song, ${ }^{\dagger, \|}$ Huajuan Wang, ${ }^{\ddagger}, \|$ Yang Wu, ${ }^{\dagger}$ Jiangjiang $\mathrm{Gu}^{\dagger}{ }^{\dagger}$ Shuojun $\mathrm{Li}^{\dagger}{ }^{\dagger}$ and Heyou Han ${ }^{*},{ }^{\dagger}+\odot$ \\ ${ }^{\dagger}$ State Key Laboratory of Agricultural Microbiology, College of Science, and ${ }^{\star}$ State Key Laboratory of Agricultural Microbiology, \\ College of Food Science and Technology, Huazhong Agricultural University, Wuhan 430070, PR China
}

\section{Supporting Information}

\begin{abstract}
Combating bacterial pathogens has become a global concern, especially the emergence of drug-resistant bacteria have made conventional antibiotics lose their efficiency. This grim situation suggests the necessity to explore novel antibacterial agents with favorable safety and strong antibacterial activity. Here, we took the advantage of quaternary ammonium compounds and synthesized a long-chain high-molecular organic bis-quaternary ammonium salt (BQAS) with a broad-spectrum bactericidal activity through a facile one-pot reaction. The bactericidal effect of BQAS was evaluated by two bacterial human pathogens: Escherichia coli (Gram-negative) and Staphylococcus aureus (Gram-positive), which are the major cause of diarrheal infections in children and adults. Our experimental results indicate that the bactericidal activity of BQAS is linked to the strong contact between the positively charged quaternary ammonium groups and the bacterial cells, thus leading to a temporary and locally high concentration of reactive oxygen species, which subsequently triggers oxidative stress and membrane damage in the bacteria. This mechanism was further confirmed by several assays, such as the

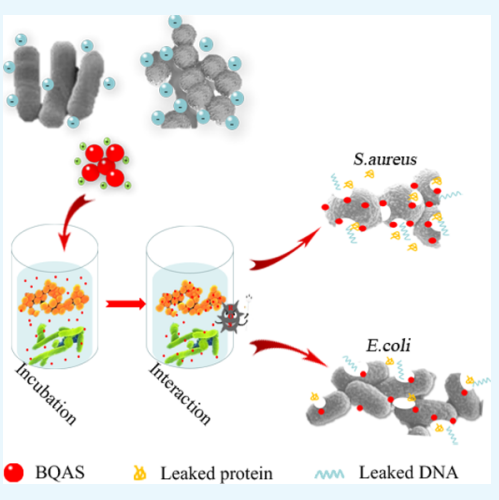
membrane permeabilization assay, fluorescent-based cell live/dead test, scanning electron microscopy, transmission electron microscopy, together with the lactate dehydrogenase release assay, which all indicated that BQAS induced damage to the cytoplasmic membrane and the leakage of intracellular fluid containing essential molecules. The excellent bactericidal activity of BQAS suggests its great application potential as a promising candidate against the rapid emergence of drug-resistant bacterial pathogens.
\end{abstract}

\section{INTRODUCTION}

Over the past decades, infectious diseases caused by bacteria remain one of the largest health problems in the world ${ }^{1}$ and afflict millions of people annually ${ }^{2}$ and thus have gained extensive concerns. More than 1.3 million deaths of children are reported to be caused by diarrheal illness worldwide every year, ${ }^{3}$ indicating the urgent necessity to develop new antibacterial agents with favorable safety and potent antibacterial activity. To this end, a variety of antibacterial materials, such as antibiotics, ${ }^{4}$ antimicrobial peptides, ${ }^{5}$ cationic polymers, ${ }^{6}$ carbon-based nanomaterials, ${ }^{7-9}$ small molecular antibacterial agents, ${ }^{10-13}$ and metals or metal oxides ${ }^{14-16}$ have been widely used in antimicrobial research. Among these traditional methods, the use of antibiotics is the most common and effective approach to treat bacterial infectious diseases. ${ }^{17}$ Despite the critical role of antibiotics in decreasing the morbidity and mortality induced by bacterial infections, ${ }^{18}$ the global abuse of antibiotics results in the development of more and more bacteria into resistance against most of the traditional antibiotics. ${ }^{19}$ The emergence of antibiotic-resistant bacteria poses a new threat to human health, ${ }^{20-22}$ further suggesting the vital importance of discovering new antibacterial materials to replace traditional antibiotics. ${ }^{23,24}$
Quaternary ammonium compounds (QACs), which are usually white and crystalline powders and are very soluble or dispersible in water, have a broad spectrum of antimicrobial activity and often display extended biological activity owing to their long-lived residues on treated surfaces. ${ }^{25}$ QACs have good antibacterial activity against both Gram-positive and Gram-negative bacteria at medium concentrations and also possess moderate effectiveness against viruses, fungi, and algae. ${ }^{26,27}$ Because of the broad-spectrum antimicrobial activity and surfactant properties, QACs, such as benzalkonium chloride, favor hygienic adjuncts in disinfectant cleaners and have been increasingly used in domestic cleaning products over the last decade. ${ }^{28}$ Several mechanisms have been suggested to explain the antimicrobial action of QACs, such as the perturbation of cytoplasmic and outer membrane lipid bilayers through the association of the positively charged quaternary nitrogen with the polar head groups of acidic phospholipids, ${ }^{29}$ followed by the interaction of the hydrophobic tail with the hydrophobic membrane core. QACs usually contain four organic groups linked to nitrogen, which may be similar or

Received: June 9, 2018

Accepted: September 25, 2018

Published: October 31, 2018 


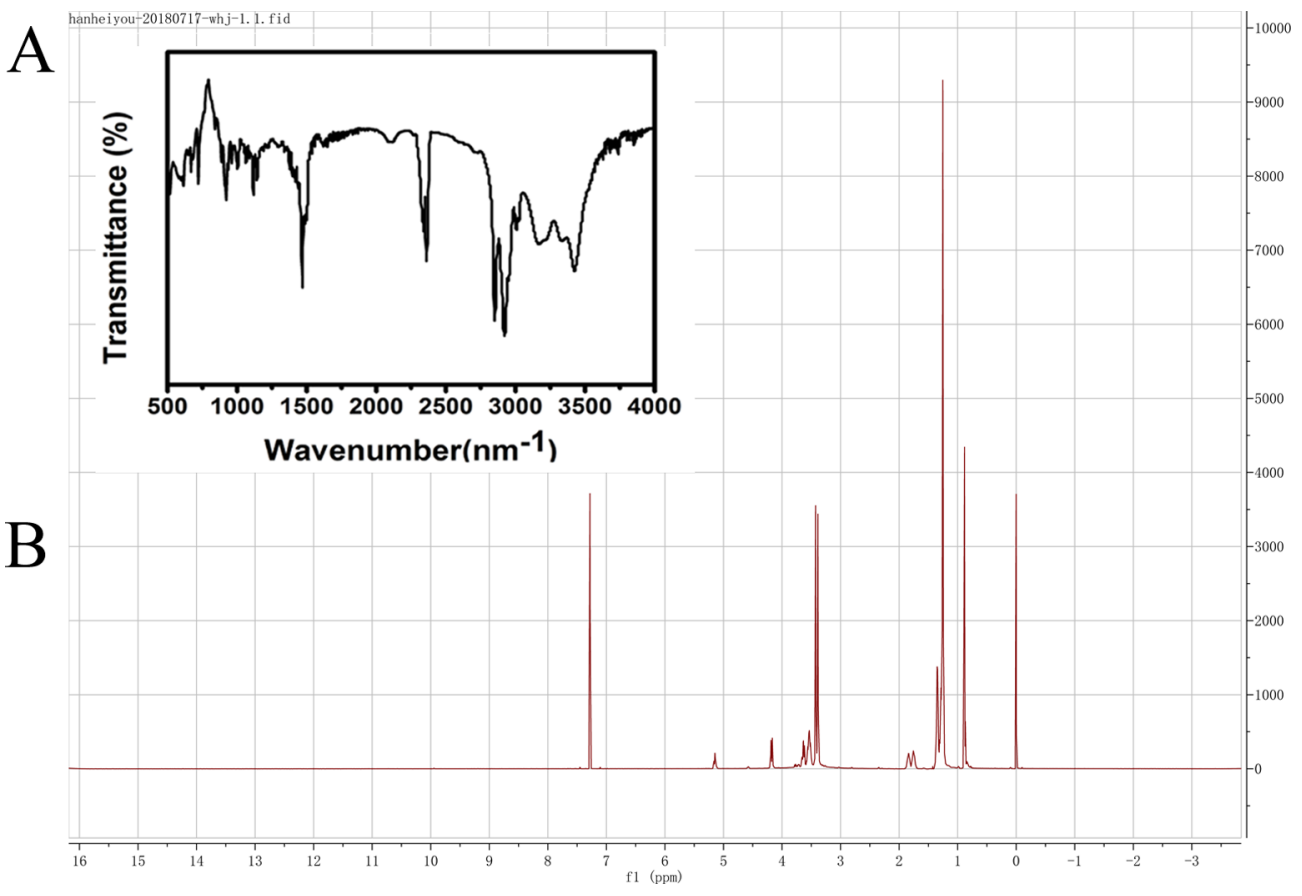

Figure 1. Characterization of BQAS by FT-IR spectroscopy (A) and ${ }^{1} \mathrm{H}$ NMR (B).

different in chemistry and structure. The organic substituents are alkyl, aryl, or heterocyclic. To achieve a hydrophobic segment compatible with the bilayer of the outer cell wall, at least one of the organic substituents should be a long alkyl chain. ${ }^{30,31}$ Previous studies have demonstrated that with an increasing alkyl chain length of an amphiphilic compound, the hydrophobic interaction with the lipid bilayer of the cell wall significantly increases, which in turn enhances the antimicrobial activity of the compound. ${ }^{32}$

In this article, we synthesized a long-chain high-molecular organic bisquaternary ammonium salt (BQAS) with excellent solubility in water by using a simple one-pot method. BQAS was found to possess both a positive charge and a hydrophobic segment, and its bactericidal properties were investigated by evaluating its bactericidal activity against the Gram-positive ( Staphylococcus aureus) and Gram-negative bacteria (Escherichia coli). The results showed that BQAS has a much stronger ability to kill bacteria at low concentrations, and the Grampositive $S$. aureus are more sensitive to BQAS than the Gramnegative E. coli. The bactericidal mechanism of BQAS was also proposed, and it had the potential as a new broad-spectrum antibacterial agent for treating infectious diseases.

\section{RESULTS AND DISCUSSION}

In this study, a simple one-step method was used to synthesize BQAS with a high yield (90\%) and a highly positive surface charge $(\zeta$-potential ca. $+30.2 \mathrm{mV})$. The molecular structure of BQAS was confirmed by nuclear magnetic resonance (NMR) and Fourier transform infrared (FT-IR) spectroscopy. The FTIR spectra of BQAS (Figure 1A) showed the absorption bands at $3390 \mathrm{~cm}^{-1}$ (O-H stretching), 2924, $2855 \mathrm{~cm}^{-1}(\mathrm{C}-\mathrm{H}$ stretching), $1468 \mathrm{~cm}^{-1}$ (C-H bending), $1124 \mathrm{~cm}^{-1}$ (C-N stretching), $1072 \mathrm{~cm}^{-1}$ (C-O stretching), and $721 \mathrm{~cm}^{-1}$ (C$\mathrm{H}$ rocking). The FT-IR spectra matched well with the molecular structure of BQAS. The ${ }^{1} \mathrm{H}$ NMR spectrum is shown in Figure $1 \mathrm{~B}$, and the peaks at $\delta 5.16(1-\mathrm{H}), \delta 3.60-4.40$ $(2-\mathrm{H}), \delta 3.40(3-\mathrm{H}), \delta 3.50(4-\mathrm{H}), \delta 1.80(5-\mathrm{H}), \delta 1.30(6-\mathrm{H})$, and $\delta 0.88(6-\mathrm{H})$ demonstrated that BQAS was successfully synthesized under the one-step pathway. The molecular characterizations of BQAS were further consolidated by electrospray ionization-mass spectrometry (ESI-MS) (positive ion). The results are shown in Figure S1. Important peaks in these spectra are found at $m / z 519.65,483.60$. These ion peaks account for the direct loss of one/two chloride ions from the molecule, leading to the formation of the positively charged ions $(\mathrm{M}-\mathrm{Cl})^{+} /(\mathrm{M}-2 \mathrm{Cl})^{+}$. These results suggested that BQAS was successfully synthesized.

The antibacterial effect was quantitatively investigated by measuring the growth curves and death rate of bacteria exposed to BQAS. The growth curve was used to study the dynamics of bacterial growth and evaluate the antibacterial properties of BQAS at different concentrations (Figure 2). In Figure $2 A, B$, an obvious growth delay could be observed with increasing BQAS concentration, indicating that the antibacterial activity of BQAS was dose-dependent. In addition, the growth delay was much more obvious in Figure $2 \mathrm{~B}$ than in Figure 2A, suggesting that $S$. aureus is more sensitive to BQAS than E. coli. Apart from growth inhibition, microbicidal activity is an important indicator for antibacterial materials. The colony count assay was carried out to study the bactericidal effect of BQAS. Figure 2C,D showed the typical photographs of the $E$. coli and $S$. aureus bacterial colonies after treatment with various concentrations of BQAS. The number of colonies was significantly reduced with an increasing BQAS concentration, indicating that BQAS has excellent bactericidal activity against both Gram-negative E. coli and Gram-positive S. aureus bacteria in a concentration-dependent manner. Meanwhile, we have selected two other strains of Methicillin-resistant $S$. aureus (1213P46B; 011P6B5A) and E. coli (EIEC 23-6; EAEC $36)$ to evaluate the minimal inhibitory concentration (MIC) of the BQAS compounds. The MIC results, as shown in Table 1 suggested that BQAS had good antibacterial effect against the Gram-positive and Gram-negative bacteria. 


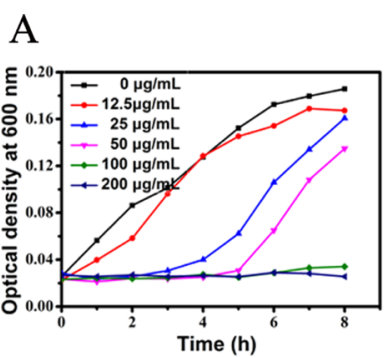

C

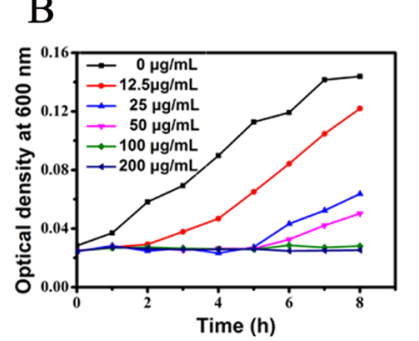

$\mathrm{D}$
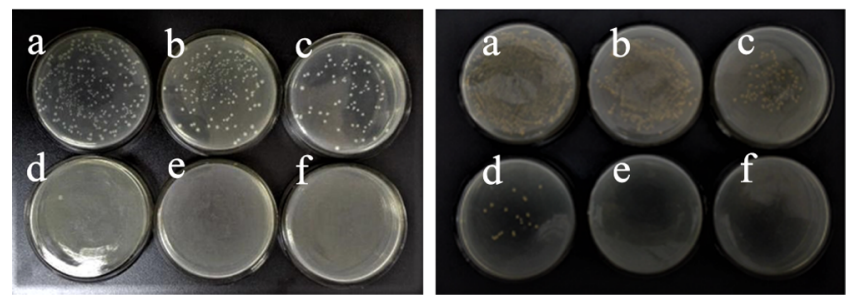

Figure 2. Growth curves of (A) E. coli and (B) S. aureus in LB medium at $30{ }^{\circ} \mathrm{C}$ after the bacterial cells $\left(200 \mu \mathrm{L}, 10^{8} \mathrm{cfu} / \mathrm{mL}\right)$ were treated with different concentrations of BQAS. Colony count assay of (C) E. coli and (D) S. aureus bacterial cells treated separately with (a) 0, (b) 12.5, (c) 25, (d) 50, (e) 100, and (f) $200 \mu \mathrm{g} / \mathrm{mL}$ of BQAS.

Table 1. MICs of BQAS Against Three Strains of GramPositive Bacteria and Gram-Negative Bacteria

$\begin{array}{lc}\text { microorganism } & \mathrm{MIC}(\mu \mathrm{g} / \mathrm{mL}) \\ \text { E. coli }(\mathrm{AB} 93154) & 16 \\ \text { E. coli (EAEC 36) } & 64 \\ \text { E. coli (EPEC 2-1) } & 32 \\ \text { S. aureus (AB 91093) } & 16 \\ \text { S. aureus (1213P46B) } & 8 \\ \text { S. aureus (011P6B5A) } & 32\end{array}$

The death rates also showed that BQAS has an excellent bactericidal activity against both Gram-negative and Grampositive bacteria. In Figure 3, the death rates gradually ascended with an increasing concentration of BQAS. The death rates for E. coli and S. aureus were 35.91 and $36.48 \%$ at the concentration of $12.5 \mu \mathrm{g} / \mathrm{mL}$, and 84.02 and $94.93 \%$ at the concentration of $25 \mu \mathrm{g} / \mathrm{mL}$, respectively. The bacterial inhibition of BQAS reached over $99 \%$ at the concentration of $50 \mu \mathrm{g} / \mathrm{mL}$, and with the concentration of BQAS increased from 12.5 to $200 \mu \mathrm{g} / \mathrm{mL}$, the death rates of both E. coli and $S$. aureus increased to $99.99 \%$. A comparison of antibacterial activity between BQAS and $\mathrm{CTAB}$ was performed under the same experimental conditions. Figure 3 showed the death rates of E. coli and S. aureus treated with CTAB $(12.5-200 \mu \mathrm{g} / \mathrm{mL})$. A significant difference of antibacterial effect could be observed between CTAB and BQAS at low concentrations. For example, BQAS showed 74 and $94.93 \%$ inactivation effect on E. coli and $S$. aureus at a concentration of $25 \mu \mathrm{g} / \mathrm{mL}$, respectively. However, CTAB exhibited only about 55.2 and $50.46 \%$ inactivation effect on the two strains at the same concentration (Figure 3). The results indicated that BQAS had a higher antibacterial activity than $\mathrm{CTAB}$ at low concentrations. Additionally, BQAS displayed a stronger inhibition effect on $S$. aureus than $E$. coli at low concentrations.

The credibility of the cfu method was further confirmed by the live/dead bacterial staining assay. PI (propidium iodide) and DAPI (4'-6-diamidino-2-phenylindole) are fluorescent dyes. PI can only pass through the damaged structures of the
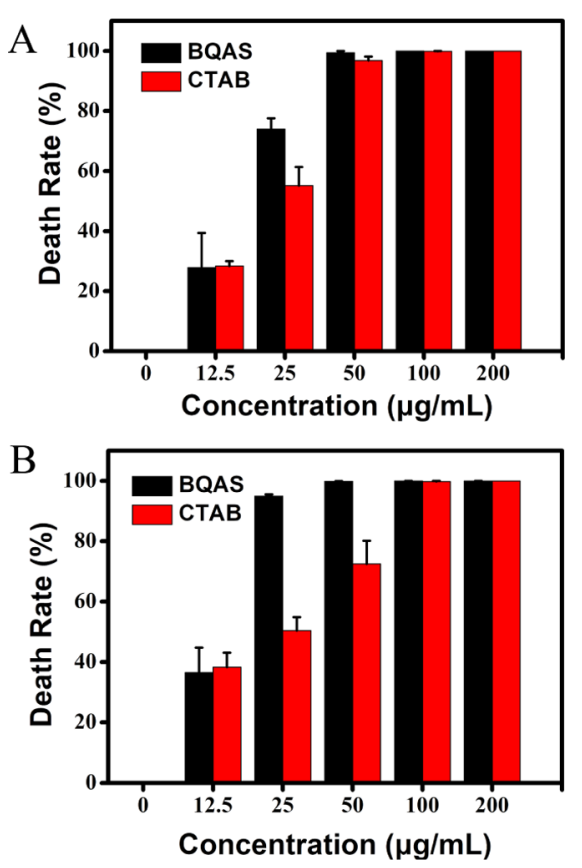

Figure 3. Cell death rates of (A) E. coli and (B) S. aureus after incubation with BQAS and $\mathrm{CTAB}$ dispersions at different concentrations $(0-200 \mu \mathrm{g} / \mathrm{mL})$ for $3 \mathrm{~h}$ at $30^{\circ} \mathrm{C}$. E. coli and $S$. aureus untreated with $\mathrm{BQAS}$ or $\mathrm{CTAB}$ were used as control. Error bars represent the standard deviation.

cell membrane, stain the nucleus, and emit red fluorescence, whereas DAPI can penetrate the intact membrane of live cells, combine strongly with DNA, and emit blue fluorescence. Therefore, PI and DAPI are usually used to identify dead cells and live cells, ${ }^{31}$ respectively. As shown in Figure 4, the red fluorescence became gradually strong and the blue fluorescence became weak with the increasing concentration of BQAS, suggesting that the dead bacterial cells ascended with the increasing concentration of BQAS. The result was not only
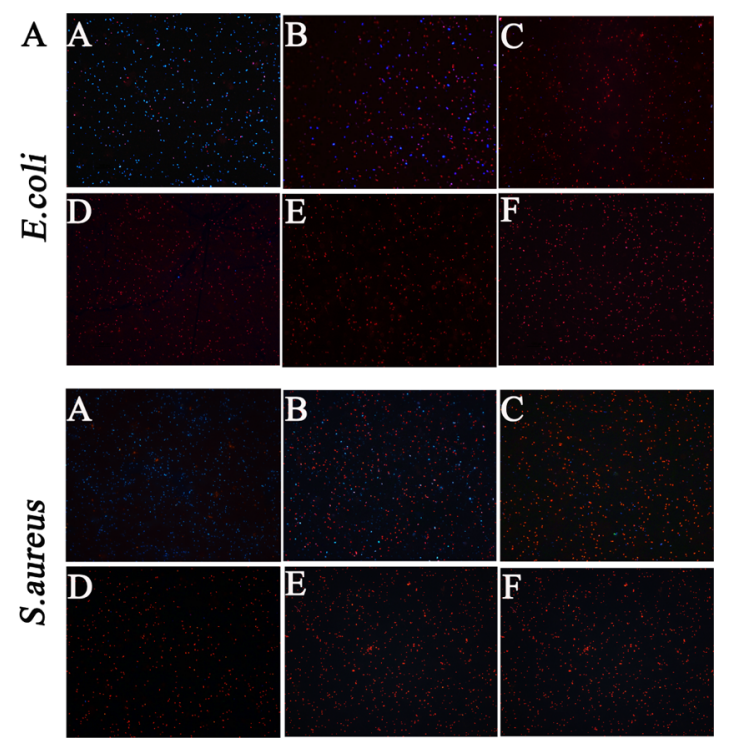

Figure 4. Fluorescence microscopic images of E. coli (top panel) and $S$. aureus (bottom panel) (cells stained with PI and DAPI) after exposure to BQAS at concentrations of (A) 0, (B) 12.5, (C) 25, (D) 50, (E) 100, and (F) $200 \mu \mathrm{g} / \mathrm{mL}$, respectively. 
in accordance with the above results, but also implied that the cell membranes were seriously damaged.

The morphological changes and membrane integrity of $E$. coli and $S$. aureus bacterial cells treated with BQAS were observed using a scanning electron microscope and transmission electron microscope. As shown in Figure 5A,C, in the
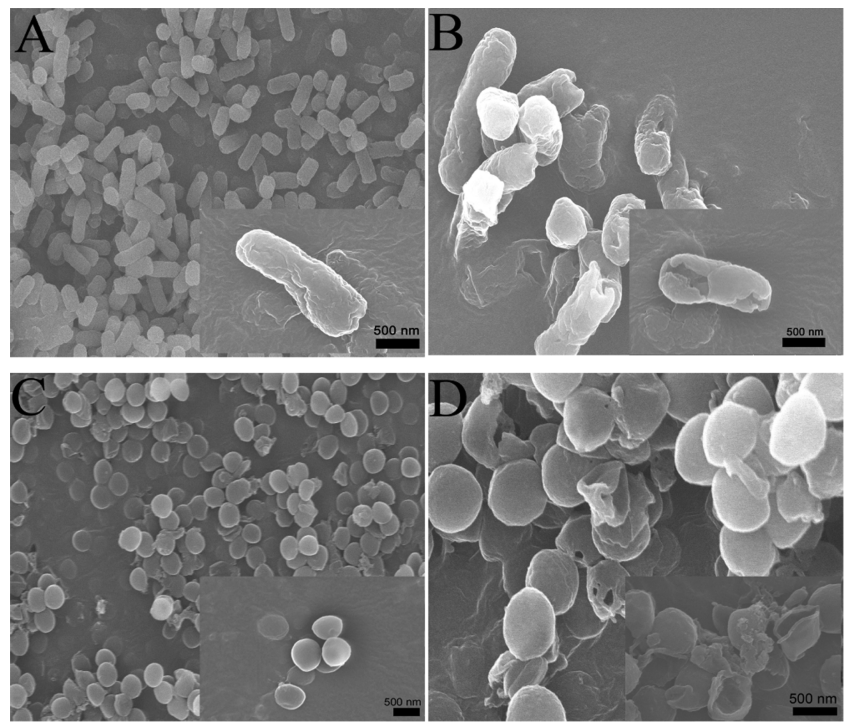

Figure 5. SEM images of E. coli (A,B) and S. aureus (C,D), untreated with BQAS (A,C) and treated with BQAS (B,D). A $200 \mu \mathrm{L}$ of BQAS $(200 \mu \mathrm{g} / \mathrm{mL})$ was incubated with $200 \mu \mathrm{L}$ of bacterial dispersion $\left(10^{8}\right.$ $\mathrm{cfu} / \mathrm{mL}$ ) for $3 \mathrm{~h}$ at a shaking speed of $120 \mathrm{rpm}$ at $30^{\circ} \mathrm{C}$.

absence of BQAS, the shapes of both E. coli and S. aureus cells were typically rod-shaped and round, respectively, with a smooth and intact cell wall to protect the bacterial cells and maintain their life. ${ }^{33}$ However, after treatment with $200 \mu \mathrm{g} / \mathrm{mL}$ BQAS, significant changes can be observed in the bacterial morphology. As shown in Figure 5B,D, a large number of $E$. coli and $S$. aureus cell walls crumpled and collapsed into holes and debris (the magnified images showed a rather clear change), leading to the inactivity of the bacterial cells.

In addition, the membrane disruption and the inner changes of the cells were confirmed by TEM (Figure 6). When the cells were treated with $200 \mu \mathrm{g} / \mathrm{mL}$ of BQAS, the bacterial cells of $E$. coli (Figure 6B) and S. aureus (Figure 6D) showed significant changes in morphology compared with the untreated bacterial cells, with the treated bacterial cell walls being blurred or the edges partially dissolved, similar to previous reports. ${ }^{34}$ These results further indicated that BQAS was an effective antibacterial agent.

The significant morphological changes in the structure of bacterial cells could be attributed to the detachment of the cytoplasmic membrane from the cell wall, as determined by the lactic acid dehydrogenase $(\mathrm{LDH})$ release assay. Figure $7 \mathrm{~A}$ exhibited the LDH activity in the supernatant after treatment with BQAS for $3 \mathrm{~h}$. It can be observed that the release of $\mathrm{LDH}$ was concentration-dependent. The bacterial cells treated with $12.5 \mu \mathrm{g} / \mathrm{mL}$ of BQAS showed a minimal release of $\mathrm{LDH}$. However, when the concentration of BQAS was increased to $200 \mu \mathrm{g} / \mathrm{mL}$, the $\mathrm{LDH}$ release significantly ascended, with a cytotoxicity of 84.2 and $83.77 \%$ for E. coli and S. aureus, respectively.

The release of cytoplasmatic content was further detected in terms of DNA and protein (Figures S4 and 7B). It can be

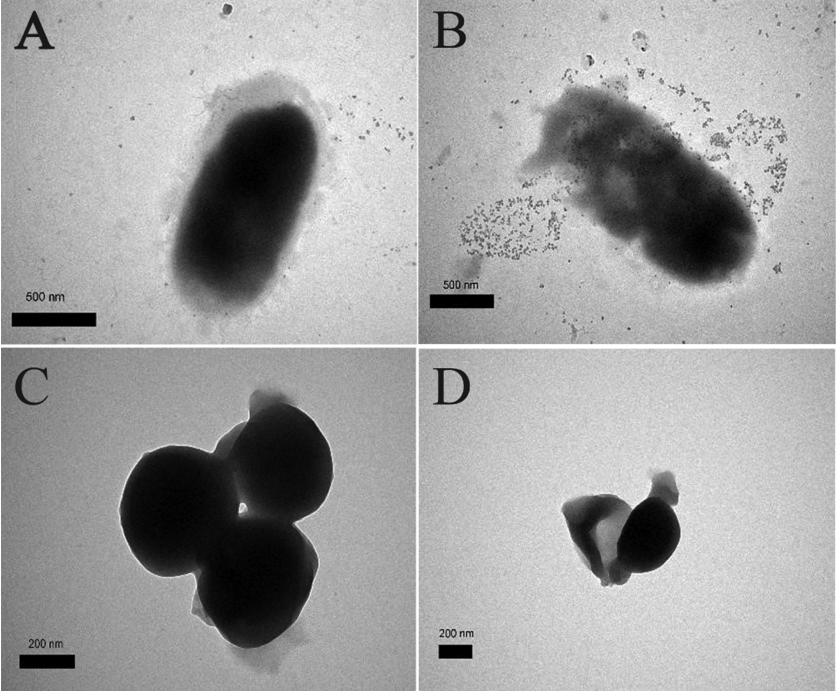

Figure 6. TEM images of E. coli $(\mathrm{A}, \mathrm{B})$ and $S$. aureus $(\mathrm{C}, \mathrm{D})$, untreated with BQAS $(\mathrm{A}, \mathrm{C})$ and treated with BQAS (B,D). A $200 \mu \mathrm{L}$ of BQAS $(200 \mu \mathrm{L} / \mathrm{mL})$ was incubated with $200 \mu \mathrm{L}$ of bacterial dispersion $\left(10^{8}\right.$ $\mathrm{cfu} / \mathrm{mL}$ ) for $3 \mathrm{~h}$ at a shaking speed of $120 \mathrm{rpm}$ at $30^{\circ} \mathrm{C}$.
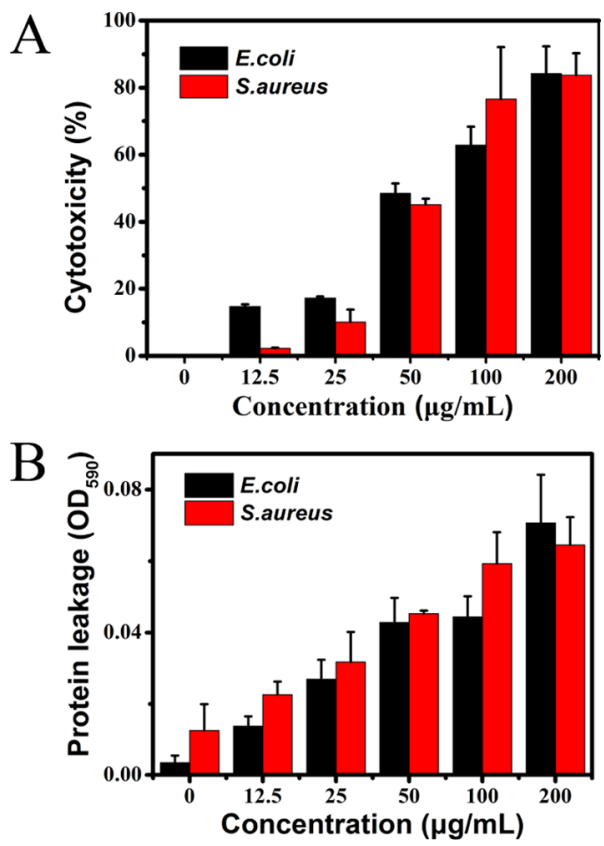

Figure 7. (A) BQAS cytotoxicity measured by the LDH release from the bacterial cells after treatment with different concentrations (0$200 \mu \mathrm{g} / \mathrm{mL}$ ) of BQAS for $3 \mathrm{~h}$. (B) Release of protein from bacteria treated with BQAS $(0-200 \mu \mathrm{g} / \mathrm{mL})$. Bacterial cells $\left(10^{8} \mathrm{cfu} / \mathrm{mL}\right)$ incubated with $200 \mu \mathrm{L}$ of different concentrations $(0-200 \mu \mathrm{g} / \mathrm{mL})$ of BQAS at $30^{\circ} \mathrm{C}$ for $3 \mathrm{~h}$ at a shaking speed of $120 \mathrm{rpm}$. Error bars represent the standard deviation $(n=3)$.

clearly seen that after incubation with different concentrations of BQAS, strips appeared. Interestingly, the intensity of the strips varied obviously with the different BQAS concentrations, the intensity of the DNA strips being stronger at low concentrations than at high concentrations. The results not only indicated that the DNA was degraded to a certain degree at a high BQAS concentration because the generated reactive oxygen species (ROS) had an activity of oxidizing the nucleic 
acid $^{35}$ but also confirmed that the cell membrane of the bacteria was indeed damaged.

Figure $7 \mathrm{~B}$ showed the leakage of proteins after interaction with BQAS. The absorbance at an optical density of $590 \mathrm{~nm}$ $\left(\mathrm{OD}_{590 \mathrm{~nm}}\right)$ reflected the level of the leaked proteins. Compared with the group untreated with BQAS, the values of $\mathrm{OD}_{590 \mathrm{~nm}}$ of the treatment groups increased with the increasing concentration of BQAS, indicating that the leakage of protein was dose-dependent. The significant increase of the leaked proteins in the bacteria verified that the bacterial cell membrane was severely damaged because of the direct contact of the bacteria with BQAS. The above results fully demonstrated that the bacterial cell walls were damaged and the inner contents leaked out, eventually leading to the inhibition of the bacterial growth.

The above results are consistent with previous studies reporting that several nanomaterials exhibited a stronger antibacterial activity against Gram-positive than Gram-negative bacteria. ${ }^{34,36}$ This difference in sensitivity to nanomaterials can be attributed to their different cell wall structures. ${ }^{37,38}$ The cellular membranes of Gram-negative E. coli have negative charges, with pI (isoelectric point) $=4-5$. However, the pI value of Gram-positive $S$. aureus membranes is higher than that of $E$. coli, which can generate a more negatively charged surface in a culture medium at $\mathrm{pH} 7$ (Figure S3). BQAS has a highly positive surface charge ( $\zeta$-potential ca. $+30.2 \mathrm{mV}$ ) and can induce a stronger contact with $S$. aureus. Previous findings have indicated that the highly positive charge causes a severe disruption of the bacterial membrane. ${ }^{39}$ To understand the mechanism of reversible antibacterial control, zeta potential measurements were carried out to study the interaction between bacteria and BQAS. As shown in Figure 8, the potentials of BQAS exhibited remarkable changes with the addition of BSA. Previous reports have shown that cationic conjugated oligomers/polymers with QA groups as side chains could bind and insert into the negatively charged membrane of bacteria by electrostatic and hydrophobic interactions. ${ }^{40,41}$

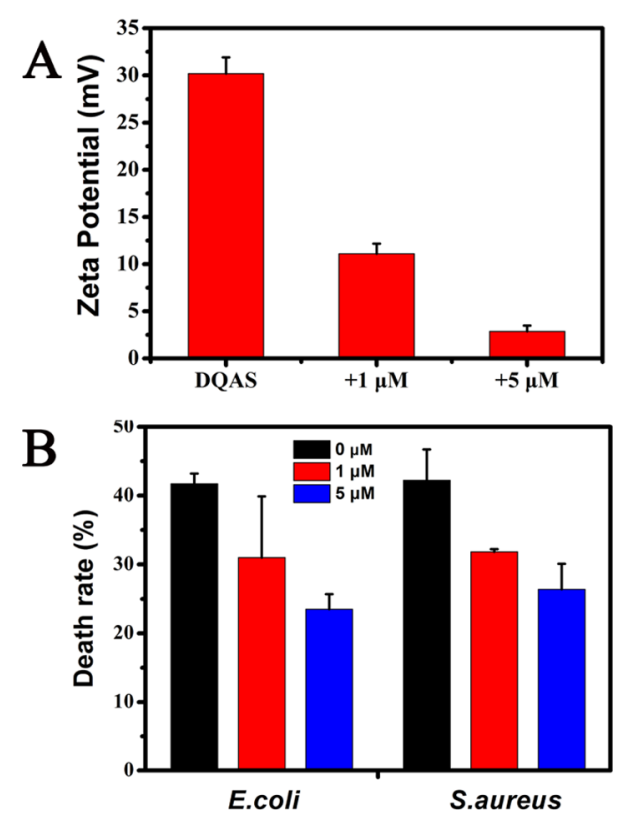

Figure 8. (A) Zeta potential of BQAS in the absence and presence of BSA and (B) death rate of $S$. aureus and E. coli for the treatments of BQAS in the absence and presence of BSA. Error bars represent the standard deviation of three repeated measurements.
Inserting into the membrane by hydrophobic interactions does not affect the zeta potential of bacteria, but binding by electrostatic interactions leads to a remarkable positive potential shift. We further measured the $\zeta$-potential and examined the antibacterial activity of BQAS. As shown in Figure $8 \mathrm{~A}$, the $\zeta$-potential values of BQAS and BQAS-BSA are significantly different; the $\zeta$-potential values of BQAS containing 1 and $5 \mu \mathrm{M}$ BSA are ca. +10 and $+3 \mathrm{mV}$, respectively. A $12.5 \mu \mathrm{g} / \mathrm{mL}$ BQAS was used to compare the antibacterial properties of BQAS with BQAS-BSA, and the results are presented in Figure $8 \mathrm{~B}$. Further, the MICs of BQAS and BSA-modified BQAS against $S$. aureus and E. coli were also measured (Table 2). It can be seen that the antibacterial

Table 2. MICs of BQAS and BSA-BQAS Against Three Strains of Gram-Positive Bacteria and Gram-Negative Bacteria

\begin{tabular}{ccc} 
& \multicolumn{2}{c}{$\mathrm{MIC}(\mu \mathrm{g} / \mathrm{mL})$} \\
\cline { 2 - 3 } microorganism & BQAS & $+5 \mu \mathrm{M}$ BSA \\
E. coli & 16 & 32 \\
S. aureus & 16 & 32 \\
\hline
\end{tabular}

activity significantly decreased with the addition of BSA, suggesting that BQAS rich in positive charge favors its antibacterial activity, leading to a strong electrostatic interaction with the bacterial membrane, and then caused severe damage to the integrity of the cell membrane, induced the leakage of intracellular contents, and ultimately resulted in bacterial death.

Several previous studies have proposed that ROS contributed to the antibacterial activity of many materials. $34,35,42,43$ Oxidative stress occurs when cells are exposed to elevated levels of ROS such as free radicals, ${ }^{\bullet} \mathrm{O}_{2}{ }^{-},{ }^{\bullet} \mathrm{OH}$, and $\mathrm{H}_{2} \mathrm{O}_{2}$. Figure 9 shows the electron spin resonance (ESR) spectra of ROS generated by BQAS in the absence of bacteria. BQAS
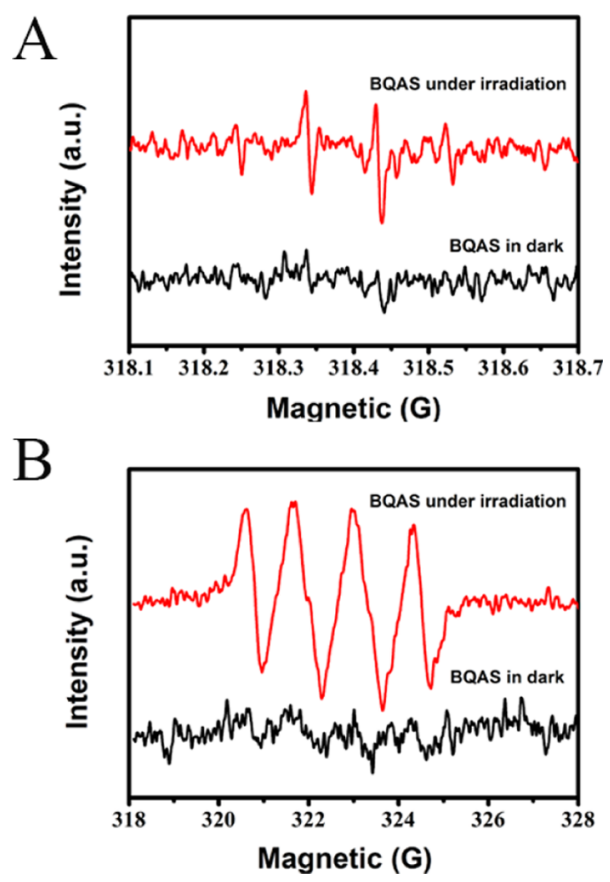

Figure 9. ESR spectra of (A) DMPO- ${ }^{\circ} \mathrm{OH}$ and (B) $\mathrm{DMPO}^{-} \mathrm{O}_{2}^{-}$for BQAS. 

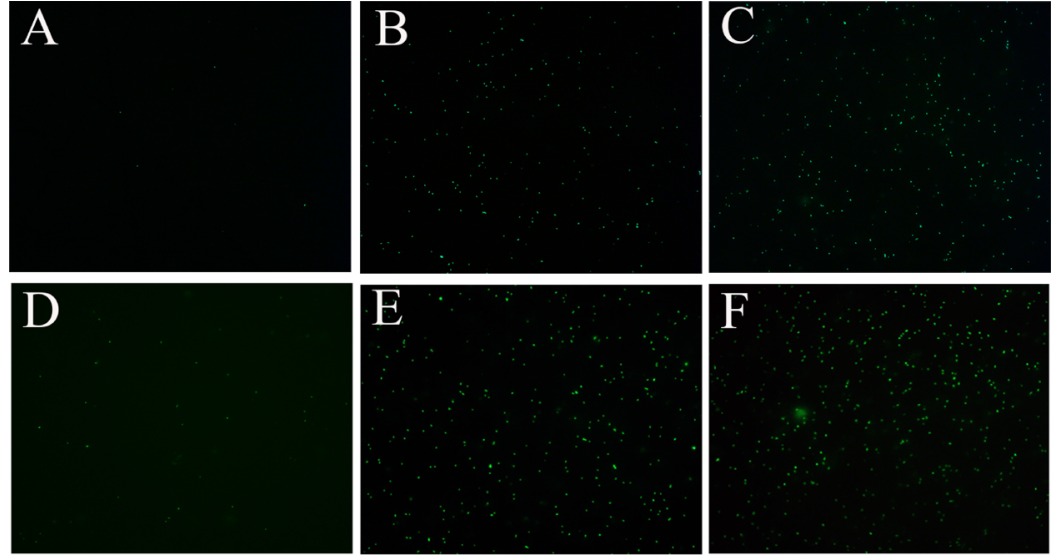

Figure 10. Intracellular ROS staining results of E. coli (A-C) and S. aureus (D-F) bacterial cells after treatment with (A) 0, (B) 50, and (C) 200 $\mu \mathrm{g} / \mathrm{mL}$ of BQAS, respectively. Bacterial suspensions in deionized water without BQAS were used as control.

generated both ${ }^{\circ} \mathrm{OH}$ (Figure 9A) and ${ }^{\bullet} \mathrm{O}_{2}^{-}$(Figure 9B) signals, with ${ }^{\bullet} \mathrm{O}_{2}{ }^{-}$as the main species.

ROS was measured with an oxidation-sensitive fluorescent probe 2,7-dichlorofluorescein diacetate (DCFH-DA). The ROS level is correlated with the antibacterial activity of the material because of its damaging effect on the bacterial cell membrane. When the materials affect the cell membrane, ROS is formed, and DCFH-DA inside the cell reacts with the ROS to form a fluorescent by-product. As displayed in Figure $10 \mathrm{~A}, \mathrm{D}$, almost no green fluorescence was observed in the absence of BQAS. However, in Figure 10B,C,E,F, the green fluorescence intensity became stronger with the increasing concentration of BQAS, demonstrating an increase of the endogenous oxidative level in this study. ${ }^{44}$ As shown in Figure S5, little green fluorescence could be observed in the absence of BQAS, implying that almost no ROS was produced. In contrast, under the treatment of $200 \mu \mathrm{g} / \mathrm{mL}$ BQAS, the green fluorescence intensity was 5.5 and 4.1 times greater than that of the control group.

The peroxidation environment makes a contribution to the physiological changes of bacterial cells, such as the depolarization of cell membrane and the release of protein and DNA/RNA, which result from the permeability increase of the membrane. ${ }^{45}$ To identify whether the cellular oxidative stress is induced by BQAS, the ROS-dependent oxidative stress was investigated. The production of superoxide anion $\left({ }^{\bullet} \mathrm{O}_{2}{ }^{-}\right)$ at different BQAS concentrations was monitored using the Superoxide Assay Kit (Beyotime Biotechnology). As shown in Figure S6, the absorption values increased notably with an increasing BQAS concentration, revealing that BQAS mediated superoxide anion production, which played an important role in antibacterial activity.

Good cell compatibility is essential for the antibacterial agents to be used in vivo. The effect of BQAS on the viability of 4T1 cells was evaluated by employing an MTT cytotoxicity assay. As shown in Figure S7, compared with the control, BQAS displayed no obvious effect on the proliferation of 4T1 cells within the concentration of $50 \mu \mathrm{g} / \mathrm{mL}$, which means that BQAS had a negligible toxicity to cells and that the cell viability was about $90 \%$. The result indicated that BQAS could be safely used in vivo.

\section{CONCLUSIONS}

In summary, our studies indicated that BQAS exhibited a broad bactericidal activity against both Gram-negative E. coli and Gram-positive $S$. aureus in vitro, and the bactericidal activity was concentration-dependent and superior to that of CTAB. Meanwhile, $S$. aureus was found to be more sensitive to BQAS than E. coli because of the different cell wall structures. BQAS has a highly positive surface charge $(\zeta$-potential ca. $+30.2 \mathrm{mV}$ ) and can induce a strong contact with the bacterial membrane. The leakage of the inner cell contents indicated that the exposure of bacteria to BQAS leads to ROS generation and the destruction of the cell membrane. This study demonstrated that the combination of a highly positive charge and ROS generation is an effective approach to improve the antibacterial activity of a bactericidal material. The integrated data indicated that BQAS had a great potential for therapy against bacterial infections.

\section{EXPERIMENTAL SECTION}

Materials. 1,3-Dichloro-2-propanol, N,N-dimethyldodecylamine, propanol, ethylacetate, PI, and DAPI products were purchased from Aladdin Industrial Corporation (Shanghai, China). The superoxide detection kit and reactive oxygen test kit were purchased from Beyotime Biotechnology (Shanghai, China). The cytotoxicity detection kit was purchased from Roche Applied Science (Shanghai, China).

Synthesis and Characterization of BQAS. BQAS was synthesized by a one-step pathway with 1,3-dichloro-2propanol and $N, N$-dimethyldodecylamine by using the condensate reflow device only. ${ }^{25,46}$ The molecular structure of BQAS was characterized by FT-IR spectroscopy and MS, and zeta potential was also used to analyze the obtained BQAS.

Bacterial Culture. E. coli ( $\mathrm{AB}$ 93154) and S. aureus ( $\mathrm{AB}$ 91093) were selected as Gram-negative and Gram-positive bacteria, respectively, and acquired from China Center for Type Culture Collection. All the bacterial strains were stored at $-80{ }^{\circ} \mathrm{C}$ in Luria Bertani (LB) with $30 \%$ glycerol. The bacteria were cultured in an LB broth medium $\left(10 \mathrm{~g} \mathrm{~L}^{-1}\right.$ peptone, $5 \mathrm{~g} \mathrm{~L}^{-1}$ yeast extract, $10 \mathrm{~g} \mathrm{~L}^{-1} \mathrm{NaCl}$, sterilization for $20 \mathrm{~min}$ at $121{ }^{\circ} \mathrm{C}$ and $101 \mathrm{kPa}$, and stored at $4{ }^{\circ} \mathrm{C}$ for further use) at $30^{\circ} \mathrm{C}$ on a shaker bed at $120 \mathrm{rpm}$ overnight. Then, the bacterial suspension was washed twice with deionized water by centrifugation $(3000 \mathrm{rpm}, 5 \mathrm{~min})$, followed by dilution with 
deionized water to a concentration of $10^{8} \mathrm{cfu} / \mathrm{mL}$ for further experiments.

Antimicrobial Activity Test of BQAS. The antimicrobial activity of BQAS was evaluated by measuring OD and by the colony count method. The OD growth curves were obtained as follows. Briefly, the logarithmic-phase bacteria $\left(0.2 \mathrm{~mL} 1 \times 10^{8}\right.$ $\mathrm{cfu} / \mathrm{mL}$ ) were centrifuged at $3000 \mathrm{rpm}$ for $5 \mathrm{~min}$ and washed in deionized water, followed by discarding the supernatant. Then, the precipitates were mixed separately with different concentrations of the BQAS aqueous solution $(12.5,25,50$, 100 , and $200 \mu \mathrm{g} / \mathrm{mL}$ ), and sterile water was used instead of BQAS as the control group. Next, the mixtures were subjected to continuous shaking at $120 \mathrm{rpm}$ and $30{ }^{\circ} \mathrm{C}$ for $3 \mathrm{~h}$ and then transferred to a $20 \mathrm{~mL} \mathrm{LB}$ medium for further incubation at 30 ${ }^{\circ} \mathrm{C}$ in a constant-temperature oscillator under $120 \mathrm{rpm}$ rotation. Finally, aliquots of the samples were withdrawn at 1 hour interval, and the value of OD at a wavelength of $600 \mathrm{~nm}$ $\left(\mathrm{OD}_{600}\right)$ was measured on a Multiskan Spectrum.

The colony count method was adopted as follows. Briefly, the bacteria $\left(1 \times 10^{8} \mathrm{cfu} / \mathrm{mL}\right)$ were incubated with different concentrations of BQAS at $30^{\circ} \mathrm{C}$ for $3 \mathrm{~h}$. The aliquots of the samples were withdrawn, and cfu was counted by plating $20 \mu \mathrm{L}$ of 10 -fold serial dilutions onto LB agar plates and cultured at $30{ }^{\circ} \mathrm{C}$ for $24 \mathrm{~h}$. The control group consisted of the bacteria untreated with BQAS. The colonies were counted, and the bacterial death rate was calculated according to the following formula

$$
\begin{aligned}
& \text { Antibacterial rate (\%) } \\
& \qquad=\left(1-\frac{\mathrm{cfu}(\text { experimental group) }}{\mathrm{cfu} \text { (control group) }}\right) \times 100 \%
\end{aligned}
$$

Fluorescence Microscopic Observation (Live/Dead). The death rates were further verified via the live/dead viability assay after treatment with BQAS. Briefly, $200 \mu \mathrm{L}$ bacterial suspensions were mixed with $200 \mu \mathrm{L}$ BQAS at different concentrations $(0,12.5,25,50,100$, and $200 \mu \mathrm{g} / \mathrm{mL})$ and incubated in a rotary shaker at $120 \mathrm{rpm}$ for $3 \mathrm{~h}$ at $30^{\circ} \mathrm{C}$. Then, an appropriate volume of the bacterial suspension was stained with PI and DAPI for 20 and $3 \mathrm{~min}$ in the dark sequentially. Finally, the fluorescence images were taken on a fluorescence microscope.

Cell Morphology Observation. SEM and TEM analyses were performed to evaluate the effect of BQAS on the morphology and structure of cells. SEM imaging was conducted as follows. Briefly, the bacterial cells were incubated with BQAS, followed by washing twice with sterile water. Then, fixation with $2.5 \%$ glutaraldehyde for $4 \mathrm{~h}$ at room temperature and successive dehydration with a gradient concentration of ethanol $(30,50,70,90$, and $100 \%)$ for 15 min were performed. Finally, the samples were dried in a vacuum oven and then coated with gold via sputtering for SEM, and the samples were dropped on copper grids for TEM.

Lactase Dehydrogenase Release Experiments. The $\mathrm{LDH}$ release assay was performed to verify the cell membrane activity of bacterial cells treated with BQAS using the $\mathrm{LDH}$ cytotoxicity assay kit (Roche Applied Science). ${ }^{47}$ The standard protocol assay was conducted according to the manufacturer's instructions. Briefly, the E. coli and S. aureus cells were treated with BQAS at concentrations of $12.5,25,50,100$, and $200 \mu \mathrm{g} /$ $\mathrm{mL}$ for $3 \mathrm{~h}$, followed by transferring $120 \mu \mathrm{L}$ of each cell culture supernatant into a new centrifuge tube and then adding $60 \mu \mathrm{L}$ of substrate. After incubation at room temperature in the dark for $30 \mathrm{~min}$, the reaction was stopped by adding $50 \mu \mathrm{L}$ of the stop solution. Finally, the $\mathrm{LDH}$ release was quantified by monitoring the absorbance at $490 \mathrm{~nm}$.

Determination of Intracellular ROS. The ROS production was evaluated by using DCFH-DA, a nonfluorescent compound, which can readily diffuse into water and interact with ROS. After incubation with different concentrations of BQAS for $3 \mathrm{~h}$, the bacterial suspensions were washed and stained with $10 \mu \mathrm{m}$ DCFH-DA (Beyotime Biotechnology) for $20 \mathrm{~min}$ in dark at $25{ }^{\circ} \mathrm{C}$. Green fluorescent ROS-producing cells were visualized with a fluorescence microscope at a 488 $\mathrm{nm}$ excitation wavelength. The areas of observation were randomly photographed with a Nikon fluorescence microscope.

The possibility of superoxide anion $\left(\mathrm{O}_{2}{ }^{\bullet-}\right)$ production was evaluated to determine the oxidative stress using the superoxide assay kit (Beyotime Biotechnology). Briefly, 200 $\mu \mathrm{L}$ of the bacterial suspension was centrifuged and washed twice with sterile water, followed by adding $200 \mu \mathrm{L}$ of detection solution and incubating at $37{ }^{\circ} \mathrm{C}$ for $5-10 \mathrm{~min}$. Next, the bacterial samples were incubated with different concentrations of BQAS under the same conditions as described above. Finally, the samples were examined by a microplate absorbance reader at $450 \mathrm{~nm}$.

Leakage of Intracellular Components. To further verify the destruction of the cell membrane, related experiments were performed to evaluate the release of protein and DNA of the bacterial cells. The protein content was measured with a BCA protein assay kit (Beyotime Biotechnology), and DNA was examined by agarose gels.

\section{ASSOCIATED CONTENT}

\section{Supporting Information}

The Supporting Information is available free of charge on the ACS Publications website at DOI: 10.1021/acsomega.8b01265.

Structural formula and MS spectrum of BQAS; antibacterial activity of BQAS; zeta potential of bacteria; DNA strides of bacterial cells; ROS generation; intracellular superoxide levels; MICs of BQAS against different strains of bacteria (PDF)

\section{AUTHOR INFORMATION}

\section{Corresponding Author}

*E-mail: hyhan@mail.hzau.edu.cn.

ORCID $\odot$

Zhiyong Song: 0000-0002-2552-5239

Heyou Han: 0000-0001-9406-0722

\section{Author Contributions}

"Zhiyong Song and Huajuan Wang contributed equally. The manuscript was written through contributions of all of the authors. All of the authors have given approval to the final version of the manuscript.

\section{Notes}

The authors declare no competing financial interest.

\section{ACKNOWLEDGMENTS}

The authors are grateful to the financial support by the National Natural Science Foundation of China (21778020), the Fundamental Research Funds for the Central Universities (grant no. 2662016QD027), Sci-tech Innovation Foundation 
of Huazhong Agriculture University (2662017PY042). The authors are also thankful to Xuedong Jia's group in the School of Chemistry and Chemical Engineering, Nanjing University for material synthesis and technical support.

\section{REFERENCES}

(1) Subbiahdoss, G.; Sharifi, S.; Grijpma, D. W.; Laurent, S.; van der Mei, H. C.; Mahmoudi, M.; Busscher, H. J. Magnetic targeting of surface-modified superparamagnetic iron oxide nanoparticles yields antibacterial efficacy against biofilms of gentamicin-resistant staphylococci. Acta Biomater. 2012, 8, 2047-2055.

(2) Rizzello, L.; Pompa, P. P. Nanosilver-based antibacterial drugs and devices: mechanisms, methodological drawbacks, and guidelines. Chem. Soc. Rev. 2014, 43, 1501-1518.

(3) Liu, C.; Xie, X.; Zhao, W.; Liu, N.; Maraccini, P. A.; Sassoubre, L. M.; Boehm, A. B.; Cui, Y. Conducting Nanosponge Electroporation for Affordable and High-Efficiency Disinfection of Bacteria and Viruses in Water. Nano Lett. 2013, 13, 4288-4293.

(4) Fischbach, M. A.; Walsh, C. T. Antibiotics for Emerging Pathogens. Science 2009, 325, 1089-1093.

(5) Shirley, D.; Chrom, C. L.; Caputo, G. A. Membrane Binding and Antimicrobial Activity of a Catioinc, Porphyrin-Binding Peptide. Biophys. J. 2017, 112, 380a.

(6) Li, P.; Poon, Y. F.; Li, W.; Zhu, H.-Y.; Yeap, S. H.; Cao, Y.; Qi, X.; Zhou, C.; Lamrani, M.; Beuerman, R. W.; Kang, E.-T.; Mu, Y.; Li, C. M.; Chang, M. W.; Leong, S. S. J.; Chan-Park, M. B. A polycationic antimicrobial and biocompatible hydrogel with microbe membrane suctioning ability. Nat. Mater. 2011, 10, 149-156.

(7) Kang, S.; Pinault, M.; Pfefferle, L. D.; Elimelech, M. Singlewalled carbon nanotubes exhibit strong antimicrobial activity. Langmuir 2007, 23, 8670-8673.

(8) Wang, X.; Liu, X.; Han, H. Evaluation of antibacterial effects of carbon nanomaterials against copper-resistant Ralstonia solanacearum. Colloids Surf., B 2013, 103, 136-142.

(9) Liu, S.; Zeng, T. H.; Hofmann, M.; Burcombe, E.; Wei, J.; Jiang, R.; Kong, J.; Chen, Y. Antibacterial activity of graphite, graphite oxide, graphene oxide, and reduced graphene oxide: membrane and oxidative stress. ACS Nano 2011, 5, 6971-6980.

(10) Ivankin, A.; Livne, L.; Mor, A.; Caputo, G. A.; DeGrado, W. F.; Meron, M.; Lin, B.; Gidalevitz, D. Role of the conformational rigidity in the design of biomimetic antimicrobial compounds. Angew. Chem., Int. Ed. 2010, 49, 8462-8465.

(11) Ghosh, C.; Manjunath, G. B.; Akkapeddi, P.; Yarlagadda, V.; Hoque, J.; Uppu, D. S. S. M.; Konai, M. M.; Haldar, J. Small molecular antibacterial peptoid mimics: the simpler the better! J. Med. Chem. 2014, 57, 1428-1436.

(12) Niu, Y.; Wang, M.; Cao, Y.; Nimmagadda, A.; Hu, J.; Wu, Y.; Cai, J.; Ye, X.-S. Rational Design of Dimeric Lysine N-Alkylamides as Potent and Broad-Spectrum Antibacterial Agents. J. Med. Chem. 2018, 61, 2865-2874.

(13) Tew, G. N.; Scott, R. W.; Klein, M. L.; DeGrado, W. F. De novo design of antimicrobial polymers, foldamers, and small molecules: from discovery to practical applications. Acc. Chem. Res. 2010, 43, 30-39.

(14) Agnihotri, S.; Mukherji, S.; Mukherji, S. Size-controlled silver nanoparticles synthesized over the range 5-100 nm using the same protocol and their antibacterial efficacy. RSC Adv. 2014, 4, 39743983.

(15) Wang, Y.-W.; Cao, A.; Jiang, Y.; Zhang, X.; Liu, J.-H.; Liu, Y.; Wang, H. Superior antibacterial activity of zinc oxide/graphene oxide composites originating from high zinc concentration localized around bacteria. ACS Appl. Mater. Interfaces 2014, 6, 2791-2798.

(16) Gupta, K.; Singh, R. P.; Pandey, A.; Pandey, A. Photocatalytic antibacterial performance of $\mathrm{TiO} 2$ and Ag-doped $\mathrm{TiO} 2$ against $\mathrm{S}$. aureus. P. aeruginosa and E. coli. Beilstein J. Nanotechnol. 2013, 4, 345-351.

(17) Ran, X.; Du, Y.; Wang, Z.; Wang, H.; Pu, F.; Ren, J.; Qu, X. Hyaluronic Acid-Templated Ag Nanoparticles/Graphene Oxide
Composites for Synergistic Therapy of Bacteria Infection. ACS Appl. Mater. Interfaces 2017, 9, 19717-19724.

(18) Kim, T. I.; Kwon, B.; Yoon, J.; Park, I.-J.; Bang, G. S.; Park, Y. K.; Seo, Y.-S.; Choi, S.-Y. Antibacterial Activities of Graphene OxideMolybdenum Disulfide Nanocomposite Films. ACS Appl. Mater. Interfaces 2017, 9, 7908-7917.

(19) Levy, S. B.; Marshall, B. Antibacterial resistance worldwide: causes, challenges and responses. Nat. Med. 2004, 10, S122-S129.

(20) Mahmoudi, M.; Serpooshan, V. Silver-coated engineered magnetic nanoparticles are promising for the success in the fight against antibacterial resistance threat. ACS Nano 2012, 6, 2656-2664.

(21) Mei, L.; Lu, Z.; Zhang, W.; Wu, Z.; Zhang, X.; Wang, Y.; Luo, Y.; Li, C.; Jia, Y. Bioconjugated nanoparticles for attachment and penetration into pathogenic bacteria. Biomaterials 2013, 34, 1032810337.

(22) Chellat, M. F.; Raguž, L.; Riedl, R. Targeting Antibiotic Resistance. Angew. Chem., Int. Ed. 2016, 55, 6600-6626.

(23) Zhao, C.; Deng, B.; Chen, G.; Lei, B.; Hua, H.; Peng, H.; Yan, $Z$. Large-area chemical vapor deposition-grown monolayer graphenewrapped silver nanowires for broad-spectrum and robust antimicrobial coating. Nano Res. 2016, 9, 963-973.

(24) Huh, A. J.; Kwon, Y. J. "Nanoantibiotics": A new paradigm for treating infectious diseases using nanomaterials in the antibiotics resistant era. J. Controlled Release 2011, 156, 128-145.

(25) McBain, A. J.; Ledder, R. G.; Moore, L. E.; Catrenich, C. E.; Gilbert, P. Effects of quaternary-ammonium-based formulations on bacterial community dynamics and antimicrobial susceptibility. Appl. Environ. Microbiol. 2004, 70, 3449-3456.

(26) Kawabata, N.; Nishiguchi, M. Antibacterial activity of soluble pyridinium-type polymers. Appl. Environ. Microbiol. 1988, 54, 25322535. PMID: 3202632.

(27) Beyth, N.; Yudovin-Farber, I.; Bahir, R.; Domb, A. J.; Weiss, E. I. Antibacterial activity of dental composites containing quaternary ammonium polyethylenimine nanoparticles against Streptococcus mutans. Biomaterials 2006, 27, 3995-4002.

(28) Gilbert, P.; McBain, A. J. Potential impact of increased use of biocides in consumer products on prevalence of antibiotic resistance. Clin. Microbiol. Rev. 2003, 16, 189-208.

(29) Jiao, Y.; Niu, L.-n.; Ma, S.; Li, J.; Tay, F. R.; Chen, J.-h. Quaternary ammonium-based biomedical materials: State-of-the-art, toxicological aspects and antimicrobial resistance. Prog. Polym. Sci. 2017, 71, 53-90.

(30) Mei, L.; Lu, Z.; Zhang, X.; Li, C.; Jia, Y. Polymer-Ag Nanocomposites with Enhanced Antimicrobial Activity against Bacterial Infection. ACS Appl. Mater. Interfaces 2014, 6, 1581315821.

(31) Muñoz-Bonilla, A.; Fernández-García, M. Polymeric materials with antimicrobial activity. Prog. Polym. Sci. 2012, 37, 281-339.

(32) Altay, E.; Yapaöz, M. A.; Keskin, B.; Yucesan, G.; Eren, T. Influence of alkyl chain length on the surface activity of antibacterial polymers derived from ROMP. Colloids Surf., B 2015, 127, 73-78.

(33) Chen, J.; Peng, H.; Wang, X.; Shao, F.; Yuan, Z.; Han, H. Graphene oxide exhibits broad-spectrum antimicrobial activity against bacterial phytopathogens and fungal conidia by intertwining and membrane perturbation. Nanoscale 2014, 6, 1879-1889.

(34) Rasool, K.; Helal, M.; Ali, A.; Ren, C. E.; Gogotsi, Y.; Mahmoud, K. A. Antibacterial Activity of Ti3C2Tx MXene. ACS Nano 2016, 10, 3674-3684.

(35) Bing, W.; Chen, Z.; Sun, H.; Shi, P.; Gao, N.; Ren, J.; Qu, X. Visible-light-driven enhanced antibacterial and biofilm elimination activity of graphitic carbon nitride by embedded $\mathrm{Ag}$ nanoparticles. Nano Res. 2015, 8, 1648-1658.

(36) Hou, J.; Miao, L.; Wang, C.; Wang, P.; Ao, Y.; Qian, J.; Dai, S. Inhibitory effects of $\mathrm{ZnO}$ nanoparticles on aerobic wastewater biofilms from oxygen concentration profiles determined by microelectrodes. J. Hazard. Mater. 2014, 276, 164-170.

(37) Fu, F.; Li, L.; Liu, L.; Cai, J.; Zhang, Y.; Zhou, J.; Zhang, L. Construction of Cellulose Based $\mathrm{ZnO}$ Nanocomposite Films with 
Antibacterial Properties through One-Step Coagulation. ACS Appl. Mater. Interfaces 2015, 7, 2597-2606.

(38) Hsu, M.-H.; Chang, C.-J. Ag-doped $\mathrm{ZnO}$ nanorods coated metal wire meshes as hierarchical photocatalysts with high visible-light driven photoactivity and photostability. J. Hazard. Mater. 2014, 278, 444-453.

(39) Jian, H.-J.; Wu, R.-S.; Lin, T.-Y.; Li, Y.-J.; Lin, H.-J.; Harroun, S. G.; Lai, J.-Y.; Huang, C.-C. Super-Cationic Carbon Quantum Dots Synthesized from Spermidine as an Eye Drop Formulation for Topical Treatment of Bacterial Keratitis. ACS Nano 2017, 11, 6703-6716.

(40) Yuan, H.; Liu, Z.; Liu, L.; Lv, F.; Wang, Y.; Wang, S. Cationic conjugated polymers for discrimination of microbial pathogens. Adv. Mater. 2014, 26, 4333-4338.

(41) Zhu, C.; Yang, Q.; Lv, F.; Liu, L.; Wang, S. Conjugated Polymer-Coated Bacteria for Multimodal Intracellular and Extracellular Anticancer Activity. Adv. Mater. 2013, 25, 1203-1208.

(42) Wang, G.; Jin, W.; Qasim, A. M.; Gao, A.; Peng, X.; Li, W.; Feng, H.; Chu, P. K. Antibacterial effects of titanium embedded with silver nanoparticles based on electron-transfer-induced reactive oxygen species. Biomaterials 2017, 124, 25-34.

(43) Courtney, C. M.; Goodman, S. M.; McDaniel, J. A.; Madinger, N. E.; Chatterjee, A.; Nagpal, P. Photoexcited quantum dots for killing multidrug-resistant bacteria. Nat. Mater. 2016, 15, 529-534.

(44) Cabiscol, E.; Tamarit, J.; Ros, J. Oxidative stress in bacteria and protein damage by reactive oxygen species. Int. Microbiol. 2000, 3, 38. PMID: 10963327.

(45) Blokhina, O.; Virolainen, E.; Fagerstedt, K. V. Antioxidants, oxidative damage and oxygen deprivation stress: a review. Ann. Bot. 2003, 91, 179-194.

(46) Tehrani-Bagha, A. R.; Kärnbratt, J.; Löfroth, J.-E.; Holmberg, K. Cationic ester-containing gemini surfactants: Determination of aggregation numbers by time-resolved fluorescence quenching. $J$. Colloid Interface Sci. 2012, 376, 126-132.

(47) Rasool, K.; Helal, M.; Ali, A.; Ren, C. E.; Gogotsi, Y.; Mahmoud, K. A. Antibacterial Activity of Ti3C2T x MXene. ACS Nano 2016, 10, 3674-3684. 